\title{
Peronismo y campo: ¿diálogo imposible? Un abordaje desde la comunicación
}

\author{
Federico Zapata \\ Candidato a Doctorado en Estudios Internacionales, \\ Universidad Torcuato Di Tella. Becario CONICET (UNSAM). \\ mzapata@mail.utdt.edu
}

Fecha de finalización del trabajo: 26 de agosto de 2020

Recibido: 27 de agosto de 2020 .

Aceptado: 30 de octubre de 2020

DOI: https://doi.org/10.26422/aucom.2020.0902.zap

\section{Resumen}

La relación entre "peronismo nacional" -en su faceta gubernamental- y "sector agropecuario" ha estado signada históricamente por tensiones y eventuales crisis de relacionamiento. Para la mirada dominante, se trata de un típico conflicto de racionalidad económica (distributivo). Este artículo propone un abordaje diferente: pensar la relación desde el punto de vista de la comunicación política. El desafío se articula a partir de una relectura original de uno de los máximos referentes del constructivismo -Alexander Wendt- aplicada a la comunicación y a la dinámica coalicional. En otros términos, se trata de un abordaje constructivista de la comunicación política, a partir de reconocer la importancia del acto comunicativo para la conformación de coaliciones sociales, en este caso, empresariales. Este giro teórico permite poner en el centro del análisis la cultura y su tensión con la comunicación. ¿Puede la comunicación política favorecer dinámicas cooperativas (coalicionales)? En caso afirmativo, ¿qué es el campo? ¿cómo hablarle y cómo no hablarle? La hipótesis constructivista aquí esbozada sostiene que si el "peronismo nacional" decide avanzar en una política de reconciliación duradera con el "sector agropecuario", no va a alcanzar con la economía (acuerdo distributivo). Deberá también redefinir su marco y horizonte discursivo sobre el sector, hacia dentro y hacia fuera. Es decir, avanzar en un proceso de redefinición identitaria. La tarea es crítica, ya que implicaría establecer una relación constructiva -coalicional empresaria- entre dos de los actores más dinámicos de la realidad argentina: el peronismo (en la política) y el campo (en la economía).

Palabras clave: comunicación, peronismo, sector agropecuario, coalición empresarial.

\section{Peronism and the agricultural sector, an impossible dialogue? Analyzing an historic rift from the point of view of political communication}

\section{Abstract \\ The relationship between Peronism - in its role as government - and the agricultural sector in Argentina has historically been marked by tension and crisis. The prevailing interpretation}


is that this conflict is fundamentally economic in nature. However, our paper proposes an alternative approach: we shall think about this relationship from the point of view of political communication. Our approach follows a unique re-reading of one of the main figures of constructivism, Alexander Wendt, applied to communication and coalition dynamics. In other words, we will take a constructivist approach to political communication, recognizing the importance of the communicative act in the conformation of social (and, in this case, state-business) coalitions. This theoretical twist allows us to place, at the center of our analysis, the question of culture and its tense meetings with communication. Can political communication be favorable to cooperative (or coalitional) dynamics? If so, what is meant by "agricultural sector"? And how would one speak - or not speak - to it? According to a constructivist hypothesis, which we will advance in what follows, if Peronism hopes to bring about a long-lasting reconciliation with the agricultural sector, it will not achieve this through purely economic measures. It must also redefine its discourse about this sector, both within the Peronist movement and without. In other words, it must redefine its own identity. This task is critical since it involves building a constructive relationship - a state-business coalition - between two of the most dynamic social actors in Argentine reality: Peronism (within politics) and the agricultural sector (within the economy).

Keywords: communication, Peronism, agricultural sector, business coalition.

\section{Peronismo e campo: pode a comunicação facilitar (ou bloquear) a emergência de uma coalizão empresarial?}

\section{Resumo}

A relação entre "peronismo nacional" -na sua faceta governamental- e "setor agropecuário" tem sido assinalada históricamente por tensões e eventuais crises de relacionamento. Para o olhar dominante, trata-se de um típico conflito de racionalidade econômica (distributivo). Este artigo propõe uma abordagem diferente: pensar a relação do ponto de vista da comunicação política. O desafio articula-se a partir de uma releitura original de um dos máximos referentes do construtivismo -Alexander Wendt- aplicada à comunicação e à dinâmica coalizacional. Em outros termos, trata-se de uma abordagem construtivista da comunicação política, a partir de assumir a importância do ato comunicativo para a conformação de coalizões sociais, neste caso, empresariais. Este giro teórico, permite colocar no centro da analise a cultura e sua tensão com a comunicação. Pode a comunicação política favorecer dinâmicas cooperativas (coalizacionais)? Em caso afirmativo, o que é o campo? Como falar com ele e como não falar? A hipótese construtivista aqui rascunhada sustenta que, se o "peronismo nacional" decide avançar numa política de reconciliação duradoura com o "setor agropecuário", não bastará com a economia (acordo distributivo). Deverá também, redefinir seu marco e horizonte discursivo sobre o setor, para dentro e para fora. Isto é, avançar num processo de redefinição identitária. A tarefa é critica, já que implicaria estabelecer uma relação construtiva - coalizacional empresária- entre dois dos atores mais dinâmicos da realidade argentina, o peronismo (na política) e o campo (na economia).

Palavras chave: comunicação, peronismo, setor agrícola, coalizão empresarial. 
Austral Comunicación

Volumen 9, número 2 (Diciembre de 2020): 429-456. ISSN 2313-9129

\section{Introducción: un punto de partida diferente}

Desde el conflicto con el sector agropecuario ocurrido en $2008,{ }^{1}$ la relación entre el peronismo nacional -en su faceta gubernamental- y el sector agropecuario dominante -sector agropecuario de la región pampeana- entró en una crisis de relacionamiento autosostenida en el tiempo. Es decir, una crisis que se autorreproduce con diferentes matices e intensidades sin la presencia de un horizonte de acuerdo estratégico común de mediano y largo plazo.

Para la mirada dominante, se trata de un típico conflicto de racionalidad económica: para el Gobierno, el sector se comporta como un actor "egoísta" incapaz de trascender las fronteras de sus intereses particulares; para el sector, el Gobierno peronista se comporta como una maquinaria extractiva que pone en riesgo la rentabilidad y el horizonte temporal que precisa la actividad para poder desarrollarse.

Este artículo propone un abordaje diferente: pensar la relación desde la comunicación política y sus tensiones con la identidad y la cultura. Es decir, desde el punto de vista de la formación de coaliciones sociales, en este caso, empresariales. Por lo tanto, no se problematizará la herramienta de recaudación y/o las intervenciones gubernamentales en el mercado, sino las acciones comunicativas que podrían favorecer un acercamiento (coalición) o bien un escalamiento (crisis).

De ninguna manera se busca desconocer el conflicto económico ni subestimar la importancia de debatir la herramienta recaudatoria o el plan sectorial (Barsky y Dávila, 2008). Todo lo contrario. Sin embargo, la hipótesis principal del presente artículo establece que si el peronismo nacional decide avanzar en algún momento en una política de reconciliación duradera con el sector, no alcanzará con resolver el conflicto distributivo. Deberá también redefinir su marco y horizonte discursivo sobre el sector, hacia dentro y hacia fuera.

Un lector escéptico cuestionará la relevancia de la comunicación, argumentando que, una vez alcanzado algún nivel mutuamente aceptable de resolución del conflicto distributivo, la comunicación es redundante. El marxismo clásico, profundamente materialista, abordó la formación de coaliciones sociales desde esta mirada. La infraestruc-

\footnotetext{
El "paro agropecuario" fue un extenso conflicto que se desarrolló durante la primera presidencia de Cristina Fernández de Kirchner, en el que las organizaciones gremiales de los productores rurales (denominada "Mesa de Enlace") tomaron medidas de acción directa contra la Resolución 125/2008, la cual establecía un sistema móvil para las retenciones impositivas a las exportaciones de soja, trigo y maíz. Las medidas de fuerza se extendieron durante 129 días (del 11 de marzo al 18 de julio). Durante el conflicto, se produjo la renuncia del ministro de Economía, Martín Lousteau. Luego de esta renuncia, la presidenta Fernández de Kirchner envió al Congreso un proyecto de ley sobre las retenciones a las exportaciones de granos y las compensaciones a los pequeños productores, con el fin de que fuera el Poder Legislativo el que resolviera la situación. Luego de ser aprobado por la Cámara de Diputados, el proyecto tuvo una votación empatada en el Senado, razón por la cual debió desempatar el vicepresidente de la Nación, Julio Cobos, quien, sorpresivamente, en la madrugada del 17 de julio, votó en contra del proyecto enviado por el Poder Ejecutivo. Al día siguiente, la Presidenta ordenó dejar sin efecto la Resolución 125/2008. La relación entre el sector agropecuario y el peronismo nacional entró en una crisis de relacionamiento que ha persistido más allá de la presidencia de Fernández de Kirchner.
} 
Federico Zapata

Peronismo y campo: ¿diálogo imposible? Un abordaje desde la comunicación

tura (relaciones de producción) resulta siempre determinante sobre la superestructura (relaciones sociales). En otros términos, la objetividad de la estructura social tiene primacía explicativa sobre la subjetividad de las relaciones sociales, políticas, culturales e ideológicas.

La economía política ha cuestionado este determinismo, subrayando la interacción entre la esfera de la economía (distribución) y la esfera de la identidad (reconocimiento). En este sentido, un ajuste en el patrón comunicativo dominante, a partir de un reordenamiento identitario, puede ser la clave para destrabar un conflicto distributivo.

Es cierto, la comunicación es un fenómeno bidireccional y el "sector agropecuario" también es parte de este juego de desencuentros. Sin embargo, el Gobierno es el dispositivo central de la comunicación política y, por lo tanto, la llave que puede transformar las reglas de juego de la arena en la que se desarrolla la relación comunicativa. Como bien entiende Mario Riorda (2006), la comunicación gubernamental puede jugar un papel clave en la construcción de consensos políticos y culturales.

En términos de María José Canel (2006), la comunicación es esencial en la toma de decisiones (información y argumentación), en la implementación de las decisiones que se toman (legitimidad que las hace vinculantes) y en la organización social (construcción de consensos y definición de horizonte estratégico).

Desde esta perspectiva, si el peronismo nacional pos-2001 decidiera avanzar en un proceso de reconfiguración de la relación con el sector agropecuario de la región pampeana, deberá reformular las respuestas que desde 2008 viene dando a dos preguntas centrales. La primera, sobre el territorio de la comunicación: ¿qué es el campo? La segunda, sobre la estrategia de comunicación: ¿ cómo hablarle -y cómo no hablarle- al campo?

¿Por qué hay dificultad para abordar y resolver un desafío de economía política que podría devolverle dinamismo a la matriz Estado-sociedad en Argentina? En parte, porque en la primera pregunta - ¿qué es el campo?- se solidifican representaciones históricas muy arraigadas en la identidad peronista. Sin embargo, el contexto de época, sumado al dinamismo y a la jerarquía del sector, obliga a generar una nueva narrativa. En otros términos, o el peronismo nacional construye un relato actualizado del sector o enfrentará problemas serios de representación política con el sector.

La dificultad para generar un ecosistema colaborativo entre el peronismo nacional -en gobierno- y el sector agropecuario de la región pampeana se inscribe en el marco de la crisis de representación que atraviesan las democracias en Occidente, las cuales se caracterizan por facilitar, cuando las dinámicas inter-élites no resultan constructivas, procesos de desafección y desacople de los territorios con relación a la representación gremial y/o corporativa. 
Austral Gmunicación

Volumen 9, número 2 (Diciembre de 2020): 429-456. ISSN 2313-9129

En el caso del sector agropecuario de la región pampeana, el debilitamiento de las entidades representativas, ante la dificultad de encontrar una solución relacional duradera con el Estado nacional, ha facilitado el surgimiento de grupos autoorganizados con agendas radicalizadas. Esta dinámica se retroalimenta negativamente con el fenómeno de origen, ya que las entidades pierden capacidad de representación, ordenación y agregación de intereses, a la par que el Estado se queda sin interlocución válida en el proceso de formulación de políticas públicas.

Queda abierto un interrogante en relación con la selección de la díada y su relevancia teórico-práctica: ¿por qué es importante pensar al peronismo y al sector agropecuario y, sobre todo, pensar la relación comunicativa entre ambos actores?

Empecemos por el peronismo. Se trata de uno de los actores principales, en términos competitivos, de la política argentina y, por lo tanto, una condición necesaria para un programa y una agenda de desarrollo. El peronismo ha gobernado 22 de los 37 años de democracia (60\%) y posee un fuerte anclaje en la política subnacional, es decir, en el gerenciamiento de estados provinciales. Sin un peronismo moderno, será difícil una Argentina moderna.

El sector agropecuario, por su parte, es un engranaje fundamental de la economía argentina, un sector competitivo, principal exportador del país, gran generador de empleo a lo largo de todas las cadenas agroalimentarias y un importante contribuyente de las arcas públicas. Desde el punto de vista territorial, las producciones agrícolas, ganaderas y agroindustriales se distribuyen en todo el país, razón por la cual los períodos expansivos de la actividad tienen un fuerte impacto federal (Bisang, Anlló y Campi, 2008).

De acuerdo con la Fundación Agropecuaria para el Desarrollo de Argentina (2019), las cadenas agroalimentarias generan 2 de cada 10 puestos de trabajo privado y $22 \%$ del empleo privado nacional, 1 de cada 10 pesos del producto bruto interno (PBI) (directo), 9,92\% del PBI argentino -y 34\% si se considera la participación sobre el PBI de bienes-, 1 de cada 9 pesos de la recaudación tributaria de la Administración Federal de Ingresos Públicos (AFIP) (directa) o el equivalente al 10,6\% de los impuestos considerados de AFIP, 6 de cada 10 dólares de las exportaciones totales del país y el 59\% de las exportaciones nacionales de bienes.

Por lo tanto, la existencia de un relacionamiento virtuoso entre ambos actores de la vida nacional resulta fundamental y la comunicación puede aportar mucho en la reconfiguración de esa potencial relación cooperativa.

En este marco, el presente trabajo se estructura en seis apartados principales. En primer lugar, se desarrolla el marco conceptual de abordaje, intentando justificar y jerarquizar la importancia de la identidad y la cultura como factores explicativos de primer orden en el diseño de estrategias de comunicación eficaces, y también en el 
Federico Zapata

Peronismo y campo: ¿diálogo imposible? Un abordaje desde la comunicación

establecimiento de relaciones sociales y políticas cooperativas (coaliciones). En el segundo apartado, se explicita la estrategia metodológica del estudio. En el tercero, se reconstruye la caja de herramientas interpretativas de la realidad ontológica, es decir, el núcleo fundamental de ideas que han estado asociadas al desarrollo agropecuario en el país. En cuarto lugar, se intenta reconstruir el núcleo básico y fundacional de la identidad peronista en relación con el sector agropecuario: "el tipo ideal". En quinto lugar, se analiza la dinámica productiva y el sujeto productor agropecuario "realmente existente". Finalmente, a partir de la disonancia entre la representación y la realidad y tomando el caso de algunas experiencias subnacionales, se plantearán algunos vectores estratégicos sobre los que podrían redefinirse los lineamientos centrales de la comunicación entre peronismo nacional y sector agropecuario, con el objetivo estratégico de facilitar una arena pública cooperativa: coalición empresaria. Decía Wolton (2005) que la comunicación, que debería aproximar a los hombres, se vuelve en realidad la que revela lo que los aleja.

\section{Marco teórico: un abordaje constructivista}

El presente trabajo implica una relectura original del máximo referente del constructivismo: Alexander Wendt (1999). En otros términos, se trata de un abordaje constructivista de la comunicación política. Ese giro teórico permite poner en el centro del análisis a la cultura y su tensión con la comunicación.

Wendt (1992), como buen internacionalista, divide a la teoría política sobre la naturaleza humana en dos campos: "realistas" y "liberales". El debate entre las dos ramas dominantes de la teoría política gira en torno a cuál es el principal determinante -o canal de influencia- de la acción política. Para los realistas, la acción política está influenciada principalmente por la estructura y la distribución de poder. Para los liberales, está influenciada principalmente por los procesos (interacción y aprendizaje) y las instituciones.

Si trasladamos el punto nodal del pensamiento moderno al plano de la comunicación, el contrato "comunicativo" de los realistas es Hobbes, mientras que el contrato "comunicativo" de los liberales es Locke (instituciones) o Rousseau (interacción y aprendizaje).

Sin embargo, nos advierte Wendt (1992), más allá de las tensiones que se expresan en el debate, ambas escuelas comparten una perspectiva: el "racionalismo" y su enfoque coasociado, "la teoría de la elección racional". Esta teoría supone que la identidad y los intereses de los actores (comunicativos en este caso) son exógenos, es decir, se toman como dados. El comportamiento de los agentes, y sus interacciones, generan resultados. En este sentido, los procesos y las instituciones cambian los comportamientos, pero no las identidades y los intereses de los agentes (Wendt, 1992). 
Austral Comunicación

Volumen 9, número 2 (Diciembre de 2020): 429-456. ISSN 2313-9129

Precisamente, el punto de partida y el aporte fundacional del constructivismo es la idea de que las identidades y los intereses son construcciones culturales y, por lo tanto, pueden ser transformados. Para el constructivismo, las identidades son una variable dependiente. Si el abordaje del presente trabajo no toma como punto de partida el conflicto económico, deberá, por añadidura, partir de una definición cultural (teoría de la identidad) y no económica de los actores (elección racional).

En otros términos, el enfoque constructivista resulta particularmente útil para el caso de estudio. En este sentido, el conflicto no sería solo una derivación lógica y causal de un conflicto distributivo entre dos actores con intereses antagónicos (ganancias relativas), sino la resultante de un proceso. En este caso, analizaremos el proceso comunicativo. Parafraseando a Wendt (1992): la estructura distributiva no tiene existencia o poder causal sin la inclusión del proceso.

En particular, el constructivismo ofrece tres vías analíticas a través de las cuales los intereses y las identidades pueden ser transformados: (1) las instituciones; (2) la evolución de la cooperación; y (3) los esfuerzos intencionales para transformar identidades egoístas en identidades cooperativas. En este último canal cumple un rol fundamental la comunicación política como medio de amplificación y transformación interactiva.

El enfoque constructivista, heredero de la tradición sociológica del interaccionismo simbólico y del estructuralismo, aporta el puente a partir del cual la comunicación política no solo se define como el canal por el que se comunican actores verticalmente (Gobierno y ciudadanos), sino también como el vector por medio del cual la comunicación política puede transformar las identidades e intereses en ambos polos de la relación.

Este enfoque, ciertamente, disuelve las fronteras entre comunicación y relaciones públicas. Como bien lo reconstruye Belén Amadeo (2016), tomando como base la definición de la Asociación de Relaciones Públicas de América (PRSA, por sus siglas en inglés), "las relaciones públicas consisten en el proceso estratégico de comunicación que construye relaciones mutuamente beneficiosas entre las organizaciones y sus públicos" (p. 156). La comunicación de gobierno emana del Poder Ejecutivo, y si bien implica una plataforma común hacia ciudadanos, también conlleva respuestas sectoriales (segmentadas). En este caso, el sector agropecuario de la región pampeana.

Siguiendo a Mario Riorda (2006), el artículo pone foco en la comunicación política como la metacomunicación de la comunicación gubernamental. Es decir, la comunicación relacional con un sector estratégico de la realidad -en países atravesados por tensiones sociales y económicas- no es solo comunicación de gestión y administración pública, sino también un metarrelato sobre la relación que se regula. En este caso, la relación entre "peronismo nacional en el Gobierno" y "sector agropecuario de la región pampeana”. 
En este sentido, se utiliza la definición de "comunicación gubernamental" de Mario Riorda (2006), entendida como "un método a través del cual un gobierno democrático intenta hacer explícitos sus propósitos u orientaciones a la opinión pública para obtener apoyo o consenso en el desarrollo de sus políticas públicas" (p. 7).

La redefinición cultural de la identidad del peronismo nacional, entendida como la condición de posibilidad de un nuevo contrato comunicativo, es una necesidad reputacional que facilitaría la sistematización de un entorno colaborativo con el sector agropecuario y, al mismo tiempo y como consecuencia de ello, permitiría políticas públicas de largo plazo, eficientes y consensuadas. En último término, la generación de una redefinición de la economía política de la relación o la posibilidad de una nueva coalición empresaria.

¿Qué es la reputación? ¿Importa en la comunicación como herramienta de la construcción de coaliciones? Siguiendo a Luciano Elizalde (2009), la reputación es el crédito social que le concede una persona a un grupo o a una organización en relación con la capacidad para llevar adelante una función. Por lo tanto, la reputación resulta central en un tablero de juego. Es un dinamizador o un obstructor de una relación en el tiempo.

En esta línea de trabajo, pueden incluirse los aportes de Orlando D'Adamo y Virginia García Beaudoux (2013) en torno a la comunicación política entendida desde la narración de historias (storytelling) y la construcción de relatos para la persuasión. El enfoque constructivista que aquí se plantea realiza dos ajustes conceptuales: en primer lugar, no se trata de la arquitectura de un relato individual, sino de un storytelling "colectivo" y "relacional"; en segundo lugar, implica una lógica revisionista de la relación, con capacidad de impacto en la gestión gubernamental: storydoing. No alcanza con reconstruir una narrativa, es preciso redefinir una identidad que permita desbloquear prejuicios históricos arraigados y, de esta manera, establecer un juego cooperativo.

En el campo de la teoría de la comunicación, Dominique Wolton es un referente en la idea de la comunicación como experiencia antropológica fundamental. Dice el autor: "Así como no existen hombres sin sociedad, tampoco existe sociedad sin comunicación" (Wolton, 2005, p. 23). Ahora bien, no existe la comunicación transparente. Comunicar siempre implica el acto de representar al otro en función de representarse a uno mismo. Es decir, comunicar es siempre un proceso de significación cultural, por lo tanto, supone una interacción opaca (una definición del otro para representarlo y hablarle), lo cual conlleva, necesariamente, malentendidos (Wolton, 2005).

En el caso de la relación del peronismo nacional -en su faceta gubernamental-y el sector agropecuario de la región pampeana -sector económico-, se fusionan las dos definiciones de comunicación de Wolton: comunicación normativa (definición de la identidad) y comunicación funcional (comunicación sectorial). El ajuste entre las dos 
dimensiones es un presupuesto del juego democrático. En otras palabras, democracia y comunicación comparten una matriz de valores y, por lo tanto, la comunicación es también una de las llaves para mejorar el funcionamiento democrático (Wolton, 2005). En la democracia, como en la comunicación, el otro es inalcanzable. Es siempre una representación. Ese margen de ajuste lo hace perfectible a la democracia (Wolton, 2005).

Así como no existe democracia sin intermediación, sin representación, tampoco existe comunicación sin ambigüedad, sin malentendidos. Ninguna técnica, dice Wolton (2005), puede eliminar la polisemia de la comunicación. Si bien el ideal de la modernidad, y de la democracia, es la racionalidad y, asociada a ella, la comprensión perfecta y transparente entre la emisión y la recepción, la comunicación política interviene en esta tensión, porque los contextos de la emisión y de la recepción son siempre diferentes: no habitamos una dimensión espacio-tiempo integrada (Wolton, 2005). Este autor dice: podemos comprimir los datos, pero no podemos comprimir ni los contextos ni los sentidos. Esta ambigüedad constitutiva del campo de la comunicación, enraizada en la ambigüedad constitutiva de la democracia representativa, es la justificación teórico-práctica de la comunicación política (Wolton, 2005).

La estrategia metodológica del presente artículo implica cruzar un momento superestructural (la representación del "peronismo nacional" sobre el "sector agropecuario") con un momento estructural ("el sujeto productor" realmente existente).

Para abordar el momento superestructural, se analizarán los discursos del líder fundacional del peronismo (Juan Domingo Perón), junto con los discursos de los dos principales referentes contemporáneos del peronismo nacional dominante hasta 2015 (Néstor Kirchner y Cristina Fernández). Es decir, el artículo evidencia una continuidad sólida en la representación fundacional (1945-1955) que opera incluso entrado el siglo XXI (2003-2015).

Una singularidad contextual: la fase fundacional de la representación se constituye en un momento de conflictividad y antagonismo (1945-1955). Por lo tanto, y como ya se señaló, no es casualidad que la reactualización de esa representación fundacional se diera a partir del conflicto en torno a la Resolución 125/2008.

\section{Estrategia metodológica: coyuntura crítica y trayectoria dependiente}

El enfoque constructivista aquí utilizado se encuadra en la tradición metodológica del "institucionalismo histórico". Siguiendo a Pierson y Scockpol (2002), tres rasgos caracterizan al institucionalismo histórico: (1) el estudio de cuestiones amplias o sustantivas; (2) el uso de la herramienta explicativa de la serie de tiempo, especificando secuencias y rastreando procesos y transformaciones de escala; y (3) el análisis de contextos macros y la utilización de hipótesis de efecto combinado a partir de la interacción entre instituciones y procesos. 
Federico Zapata

Peronismo y campo: ¿diálogo imposible? Un abordaje desde la comunicación

La relación causal se da, en este marco, a partir del poder explicativo de una representación fundacional ("coyuntura crítica") con relación a acontecimientos posteriores. Es decir, se trata de un marco interpretativo con poder explicativo sobre la conflictividad contemporánea.

En este sentido, se trata de una relación causal teórica (cualitativa), no de una correlación entre dos variables (cuantitativa). Es un encuadre metodológico propicio para el estudio de la comunicación política.

Dos conceptos resultan centrales para pensar el caso y la construcción de una identidad: "coyuntura crítica" y "trayectoria dependiente". La trayectoria dependiente (o path dependence) es, en términos de Pierson y Scockpol (2002), "la dinámica de los procesos de retroalimentación positiva en un sistema político" (p. 13), en este caso, de un sistema de ideas, al interior de una cultura. Lo que los economistas llaman procesos de "rendimientos crecientes" (Pierson y Scockpol, 2002, p. 13). Por su parte, los procesos dependientes de la trayectoria estrictamente definidos involucran una lógica clara: los resultados en una "coyuntura crítica" desatan mecanismos de retroalimentación que refuerzan la recurrencia de un patrón particular en el futuro (Pierson y Scockpol, 2002).

Existen fuertes bases teóricas que sustentan la tesis de que los procesos que se retroalimentan son centrales en la vida política (Pierson y Scockpol, 2002). Una vez que se establecen los patrones de movilización política, las "reglas del juego" institucionales, e incluso las formas ciudadanas básicas de pensar acerca del mundo político, también se sientan las bases para generar dinámicas de retroalimentación (Pierson y Scockpol, 2002).

Por lo tanto, el argumento teórico sobre el path dependence nos advierte de la centralidad causal -y conceptual- de las "coyunturas críticas" o momentos formativos, permitiendo echar luz sobre la inercia que caracteriza muchos aspectos del desarrollo político, cultural y comunicacional (Pierson y Scockpol, 2002).

En el caso bajo indagación, y como ya se mencionó, la coyuntura crítica es el momento fundacional de una identidad política, el peronismo, entre 1945 y 1955. La hipótesis central de trabajo implica que las definiciones fundacionales de una identidad tienen un rol causal más allá de ese período histórico, sobre todo en momentos en los que, sujetos de esa cultura, deben construir un relato o una explicación en torno a procesos o conflictos que involucran sujetos históricos de los que se carece de una referencia empírica actualizada.

Siguiendo a Arthur Stinchcombe (1987), se trata de utilizar una "causalidad histórica" en la que las dinámicas desatadas por un evento o proceso en un punto en el tiempo se reproducen, incluso en ausencia de la recurrencia del evento o proceso original. 
Austral Comunicación

Volumen 9, número 2 (Diciembre de 2020): 429-456. ISSN 2313-9129

En este marco, la estrategia metodológica se ordena en cinco momentos, atravesados transversalmente por definiciones muestrales.

En primer lugar, como la teoría constructivista postula, el peronismo no inventa de la nada un discurso sobre el sector, sino que construye un relato a partir del "estado del arte" de las ideas en torno al desarrollo capitalista del sujeto agropecuario. En la Argentina, y en el mundo, ese nucleamiento de ideas se estructura en la denominada "sociología rural". Desde el punto de vista de la muestra, el "estado del arte" de la sociología rural se reconstruye a partir de la selección de dos autores especializados en historia de las ideas rurales -de amplio reconocimiento en la comunidad científicaque sistematizan las principales corrientes al interior del campo académico: Roy $\mathrm{Hora}^{2}$ y José Muzlera. ${ }^{3}$

En segundo lugar, se analizará la matriz discursiva del primer peronismo gubernamental a escala nacional (1945-1974) con el objetivo de construir un "tipo ideal" de la representación fundacional de la identidad en relación con el recorte sectorial: el sector agropecuario. La coyuntura crítica de la representación. Desde el punto de vista de la muestra, se utilizará el trabajo de Mario Lattuada, ${ }^{4}$ un estudioso de amplio reconocimiento en la comunidad científica especializado en el mundo de las ideas del peronismo con respecto al sector agropecuario.

En tercer lugar, se abordará el territorio, es decir, el "sujeto agropecuario realmente existente". Para esta finalidad, se utilizarán datos estadísticos extraídos de los censos agropecuarios y entrevistas en profundidad realizadas en las provincias de Córdoba y Santa Fe, a través de la herramienta de "bola de nieve" con criterio de saturación. ${ }^{5}$ En este caso concreto (sector agropecuario), se estableció una relación con directivos de la Asociación de Cooperativas Argentinas, que agrupa a unas 140 cooperativas con 50 mil productores, quienes facilitaron el acceso a casos testigo en la geografía seleccionada que, a su vez, permitieron -a partir de referencias secundarias- identificar nuevos casos hasta saturar el universo discursivo.

En cuarto lugar, se analizarán los discursos sectoriales de Cristina Fernández y de Néstor Kirchner en el contexto de la crisis en torno a la Resolución 125/2008, a fin de determinar si existe una reutilización de la matriz cognitiva fundacional de la identidad en cuestión (1945-1955). Es decir, como en el caso del momento fundacional, no se despliega un análisis general e inductivo del discurso del peronismo a lo largo del tiempo, sino más bien un análisis sectorial y focalizado: ¿cuáles son las ideas del

\footnotetext{
Se estudiaron en profundidad los siguientes textos de producción académica de Roy Hora $(2010 ; 2015 ; 2018)$.

Se estudiaron en profundidad los siguientes textos de producción académica de José Muzlera (2008a; 2008b; 2009a; 2009b; 2013).

4 Se estudiaron en profundidad los siguientes textos de producción académica de Mario Lattuada (1986; 2002).

5 Las entrevistas se enmarcan en el proyecto de investigación para la realización de la tesis doctoral en torno a la economía política del desarrollo y coaliciones empresariales.
} 
Federico Zapata

Peronismo y campo: ¿diálogo imposible? Un abordaje desde la comunicación

peronismo nacional en relación con el sector agropecuario de la región pampeana? La importancia de la crisis en la selección es fundamental, debido a que la conflictividad y el antagonismo son el momento sociopolítico central para construir un clivaje, una identidad y una reputación.

En quinto lugar, y para finalizar, se generará una serie de hipótesis dialógicas (estrategias comunicativas) que podrían favorecer la emergencia de una dinámica cooperativa entre "el peronismo nacional" y "el sector agropecuario de la región pampeana". A tal fin, se utilizará un caso subnacional exitoso en tal sentido: el peronismo de la provincia de Córdoba.

\section{La caja de herramientas: las "ideas" en torno al desarrollo agropecuario}

El peronismo (1945-1955) es contemporáneo a la institucionalización de la sociología científica en la Argentina. De hecho, y de alguna manera, podría decirse que esta nace de la necesidad de explicar esa inmensa transformación social que es la emergencia de la sociedad de masas, que en Argentina tiene como protagonista al peronismo. La figura emblemática de este giro es Gino Germani, que en 1957 participa de la creación de la carrera de Sociología en la Facultad de Filosofía y Letras de la Universidad de Buenos Aires.

En ese entorno floreciente de ideas, el abordaje que primó en la sociología argentina para explicar la ruralidad fue el marxismo. Este resulta, por lo tanto, un punto de partida ineludible para pensar la caja de herramientas conceptuales (ideas) disponibles en Argentina para pensar el campo. Siguiendo a José Muzlera (2013), el marxismo incluyó tres vías de abordaje sobre la ruralidad: la vía "clásica" o inglesa (elaborada por Karl Marx), la vía junker o alemana (elaborada por Karl Kautsky) y la vía farmer o norteamericana (elaborada por Vladimir Lenin). Desarrollemos los tres derroteros de ideas.

Marx analiza la cuestión agraria en El capital a partir del concepto de "renta". El capitalismo como modo de producción, de acuerdo con Marx (2002), implica tres sujetos productivos: (1) los terratenientes o dueños de la tierra, que se apropian de la renta; (2) los arrendatarios o capitalistas, que invierten en los medios de producción y se organizan para obtener una ganancia; y (3) los asalariados rurales, que son dueños de su fuerza de trabajo y la venden en el mercado para poder reproducirse.

En Marx, nos dice Muzlera (2013), el campesino es un sujeto residual del sistema feudal que tiende a desaparecer con el desarrollo de las fuerzas productivas.

Kautsky (1983) aborda la ruralidad en La cuestión agraria. Allí, a partir de analizar el caso prusiano, describe la vía junker hacia el desarrollo capitalista agrario: básicamente, el terrateniente de origen feudal lidera el desarrollo capitalista rural. Se trata de un desarrollo "desde arriba". El terrateniente utiliza la fuerza de trabajo, pero también, 
Austral Comunicación

Volumen 9, número 2 (Diciembre de 2020): 429-456. ISSN 2313-9129

como en el análisis de Marx, el campesinado es un sujeto residual tendiente a desaparecer (Muzlera, 2013).

Lenin (1957) aborda su concepción de la ruralidad en su obra emblemática "El desarrollo del capitalismo en Estados Unidos". Allí se aparta de las dos contribuciones centrales del marxismo para poner en el centro de la escena la hipótesis del rol de los sujetos no capitalistas en el desarrollo del capitalismo agrario (Muzlera, 2013). En otros términos, para Lenin, sujetos no capitalistas pueden dar origen a un agro capitalista vía una modalidad alternativa a la descripta por Marx y Kautzky: la vía farmer, o desarrollo capitalista "desde abajo", típica de los Estados Unidos.

En esta vía, la producción estaba a cargo de pequeños y medianos productores, que eran propietarios de la tierra y de los medios de producción y explotaban su propia fuerza de trabajo en el desarrollo sectorial (trabajo familiar). A diferencia del sujeto campesino, el productor incorpora capacidad de acumulación, por lo tanto, se vuelve estable. Es decir, el desarrollo capitalista se produce con ellos y no a expensas de ellos (Muzlera, 2013).

Esta mirada original de Lenin sobre el desarrollo capitalista rural, sustentado en la experiencia singular de los Estados Unidos, tuvo un desarrollo autóctono en Argentina: las ideas de Sarmiento (1978) en Facundo. Civilización y barbarie. Se trata de una de las obras más influyentes del pensamiento nacional, propia de la etapa presociológica, pero con fuerte impacto en la configuración de la sociología institucional y del pensamiento político nacional.

Como bien lo identifica Roy Hora (2018), Sarmiento escribe Facundo. Civilización $y$ barbarie en 1845, en pleno apogeo del rosismo, e identifica a la "estancia ganadera" como la formación sociocultural de la barbarie y el atraso nacional. De hecho, el rosismo era, para el político-intelectual, un "aborto de la estancia". Es decir: (1) la estancia se identificaba con la gran propiedad de la región pampeana; (2) esa unidad productiva había tenido su génesis con el rosismo; (3) la estancia era el obstáculo para una sociedad de hombres libres.

Visto a la distancia, resulta paradójico; pero, efectivamente, el rosismo era la génesis del poder terrateniente. En otros términos, el campo era la fuente de donde brotaba la riqueza nacional, pero también la fuente de sus problemas políticos (Hora, 2018).

En este marco, Sarmiento edifica su proyecto político a partir de la idea de los farmers: pequeños y medianos productores. Es decir, y por una vía diferente, tanto Sarmiento como Lenin encuentran una singularidad en la trayectoria de los Estados Unidos. En el caso de Lenin, se trata de un análisis que advierte sobre posibles escollos en la superación del capitalismo. En el caso de Sarmiento, se trata de la identificación de una variante empírica que puede constituir el germen de un proyecto político: la 
Federico Zapata

Peronismo y campo: ¿diálogo imposible? Un abordaje desde la comunicación

utopía de Thomas Jefferson, en la cual la condición de posibilidad de la democracia era la pequeña propiedad rural (Hora, 2018).

La frondosa agenda gubernamental de época es inexplicable sin el trasfondo de las ideas de Sarmiento: Ley de Inmigración de Avellaneda (1876), Leyes de Tierras (1857), Ley de Centros Agrícolas de Buenos Aires (1883), Programa de Colonias de Entre Ríos y Santa Fe (Hora, 2018).

El contrapeso del proyecto político de Sarmiento serán las ideas de Mitre, quien sostenía que la gran propiedad era inevitable en un país con ausencia de capital, población y grandes extensiones de tierra (Hora, 2018). La pequeña propiedad creció en Entre Ríos, Córdoba y Santa Fe, mientras que en la Buenos Aires otrora de Rosas -y, a partir de su caída, poderío de Mitre- siguió siendo el epicentro de la gran propiedad (Hora, 2018).

\section{La coyuntura crítica: el "campo" para el "peronismo"}

Sobre este sustrato de ideas -las aportadas por la sociología (Marx, Kautzky y Lenin) y las provenientes del pensamiento nacional (Sarmiento)-, el peronismo generaría un abordaje original sobre la cuestión rural (Hora, 2018).

Reelaborando el abordaje de Mario Lattuada (2002), es posible afirmar que el peronismo edificó un discurso sobre la cuestión agraria anclado en un pilar social, uno económico y otro político: la cosmovisión peronista sobre el campo.

Desde el punto de vista social, el peronismo se autoconcibe como un movimiento de integración de trabajadores industriales sindicalizados que, en muchos casos, fueron inmigrantes rurales del "interior" expulsados de sus terruños y radicados en el Río de la Plata (la tesis Gino Germani). No es casual que en el joven peronismo (1945 y antes) la figura del "peón" rural tuviera un rol central (Lattuada, 2002).

Desde el punto de vista económico, el peronismo sostiene que el orden mundial sigue un esquema centro industrial-periferia agrícola, razón por la cual se produce un deterioro estructural de los términos de intercambio en el comercio internacional en perjuicio de los países periféricos, que reproduce el subdesarrollo y amplía la brecha entre países desarrollados y países subdesarrollados (Lattuada, 2002).

Desde el punto de vista político, y como corolario de los pilares sociales y económicos, el peronismo funciona como el canal de expresión y representación de la contradicción principal: pueblo (trabajador) frente a oligarquía, identificada esta última con sectores dominantes ligados a la economía agropecuaria (Lattuada, 2002).

En síntesis, siguiendo a Lattuada (2002), para el peronismo clásico -forjado al calor de la década del 40-, el sector agropecuario era un sistema desigual de producción basado en trabajo indirecto (arrendatarios y aparcerías), con una estructura caracterizada por la desigual distribución de la tierra, el ingreso y el poder y que tenía en su 
Austral Comunicación

Volumen 9, número 2 (Diciembre de 2020): 429-456. ISSN 2313-9129

cúspide a los terratenientes, quienes, a su vez, integraban la oligarquía dominante argentina. Para el peronismo (1945-1955), nos dice Roy Hora (2018), el campo se transforma en un problema económico: el latifundio como problema económico.

Desde el punto de vista de las ideas, se trata de un abordaje fuertemente influido por la tesis de Kautzky: el desarrollo agropecuario "desde arriba".

Esta cosmovisión de ideas sobre el sector agropecuario iluminó el conjunto de políticas públicas sectoriales y también la matriz de conflictos sociales entre el peronismo clásico y el "campo" realmente existente en la primera y segunda presidencia de Perón (1946-1952 y 1952-1955, respectivamente). De hecho, las políticas públicas, de algún modo, también son ideas ejecutadas en planes y programas. Es decir, las políticas que derivan de la matriz principal de pensamiento sobre el sector también forman parte de la cosmovisión fundacional:

1. Si el comercio internacional se caracterizaba por la presencia de términos de intercambio negativos para los bienes agropecuarios, era necesario impulsar un agresivo proceso de industrialización nacional.

2. Con la interrupción del comercio internacional producto de las dos grandes guerras, el modelo de país basado en la exportación de materias primas y la importación de bienes de capital, energía y bienes industriales entró en crisis. Era necesario superar la dependencia argentina (Hora, 2018).

3. Por lo tanto, la política económica debía impulsar la industrialización y el desarrollo autónomo en desmedro de la agricultura (la tesis modelo industrialización por sustitución de importaciones).

4. Esto implicaba promover un proceso de crecimiento endógeno, basado en la expansión del mercado interno como fuente de oferta y demanda y en un papel más activo del sector público como orientador de la inversión y el consumo y, con las limitaciones propias de la situación, también como proveedor de tecnología y capital (Hora, 2018).

5. Este vuelco suponía darle la espalda al campo para hacer del sector industrial el principal agente del proceso de diversificación de la estructura productiva y el núcleo a partir del cual construir una sociedad más moderna e integrada, y también más justa (Hora, 2018).

6. Desde entonces, el sector rural pasó a entenderse como una instancia subsidiaria de una estrategia de desarrollo que, orientada y empujada por el Estado, tenía su atención y sus esperanzas puestas en el sector manufacturero (Hora, 2018). 
En síntesis, siguiendo a Roy Hora (2018), para Perón, el sector agropecuario tendría dos funciones centrales en la nueva estrategia de desarrollo industrial anclado al mercado interno: por una parte, debía proveer las divisas necesarias para importar los bienes de capital y los insumos requeridos para empujar el crecimiento de la manufactura; por la otra, tendría que generar una amplia oferta de alimentos a bajo precio para satisfacer las demandas de consumo popular y elevar el nivel de vida de la población urbana.

No quiero terminar sin enviar un recuerdo cariñoso y fraternal a nuestros hermanos del interior que se mueven y palpitan al unísono con nuestros corazones en todas las extensiones de la patria. A ellos, que representan el dolor de la tierra, vaya nuestro cariño, nuestro recuerdo y nuestra promesa de que en el futuro hemos de trabajar a sol y a sombra porque sean menos desgraciados y puedan disfrutar mejor de la vida (Perón, 1945, p. 3).

No somos enemigos del capital, aun foráneo, que se dedica a su negocio; pero sí lo somos del capitalismo, aun argentino, que se erige en oligarquía para disputarle a la nación el derecho de gobernarse por sí, y al estado el privilegio de defender al país contra la ignominia y contra la traición (Perón, 1952, p. 35).

Encontramos un país condenado por sus amos a trabajar exclusivamente en la producción agropecuaria. Nosotros decidimos realizar la industrialización de la República. (Perón, 1952, p. 43)

Nosotros iniciamos la industrialización del país. Es decir, fuimos convirtiendo una masa rural en una masa urbana organizada. Por eso, cuando empezamos a trabajar sobre sueldos y salarios, preferentemente se empezó por el trabajador rural. Desde Trabajo y Previsión, la primera reforma de fondo que se hizo fue el Estatuto del Peón. La situación de esos obreros rurales era muy próxima a la esclavitud y algunas veces peor (Perón, 1973, p. 1).

¿Tiene alguna relevancia una cosmovisión de ideas sobre un sector económico en un líder esencialmente pragmático? La pregunta admite varias respuestas.

Lo que aquí estamos indagando es el poder de un conjunto de ideas elaboradas por el peronismo fundacional sobre experiencias posoriginarias. Es decir, no importa tanto el peso de ese conjunto de ideas en Perón como su peso explicativo en el peronismo sin Perón. De hecho, el Perón de 1952, posterior a la crisis del trigo, tuvo un abordaje muy pragmático del sector, que implicaba poner entre paréntesis la construcción conceptual aquí descripta.

Sin embargo, aquí interesa menos el artista -el creador del mito-, el líder y sus giros pragmáticos como los dogmáticos, el conjunto de referentes posoriginarios que deben sobreactuar la pertenencia a una cultura política, o bien que en contextos de crisis e incertidumbre, y ante la carencia de un referente empírico, recurren al mito fundacional.

También pueden existir liderazgos posoriginarios pragmáticos, sin embargo, deben siempre contener a la minoría intensa de una corriente política y, por lo tanto, reactualizar los relatos y mitos fundacionales. Esto resulta particularmente pernicioso si el mito fundacional describe en forma distorsionada la realidad. Pensar al sector agropecuario en el siglo XXI desde categorías originadas en el siglo XX resulta en una distorsión mayúscula. 
Austral Comunicación

Volumen 9, número 2 (Diciembre de 2020): 429-456. ISSN 2313-9129

\section{El territorio: ¿qué es el campo?}

Siguiendo el trabajo de José Muzlera (2013), definiremos al sujeto productor "realmente existente" -al "campo" o "sector agropecuario"- a partir de cuatro dinámicas y/o dimensiones centrales: delimitación geográfica, excepcionalidad del caso argentino, relativa estabilidad del sujeto productor y tipología de actores (subtipos).

En primer lugar, comenzaremos delimitando geográficamente el concepto. Cuando hablamos de "campo" no nos estamos refiriendo a la totalidad de la realidad rural existente en el territorio, sino a un referente localizado en la región pampeana (Buenos Aires, parte de La Pampa, Santa Fe, parte de Entre Ríos y de Córdoba). Desde los orígenes de la Argentina, nos dice Muzlera (2013), como consecuencias de sus características logísticas (cercanía a los puertos) y naturales (clima y suelo), se trata de la región con mayor dinamismo en el territorio nacional. Entonces, y en principio, cuando hablamos de "campo" hablamos del "agro pampeano" (Muzlera, 2013).

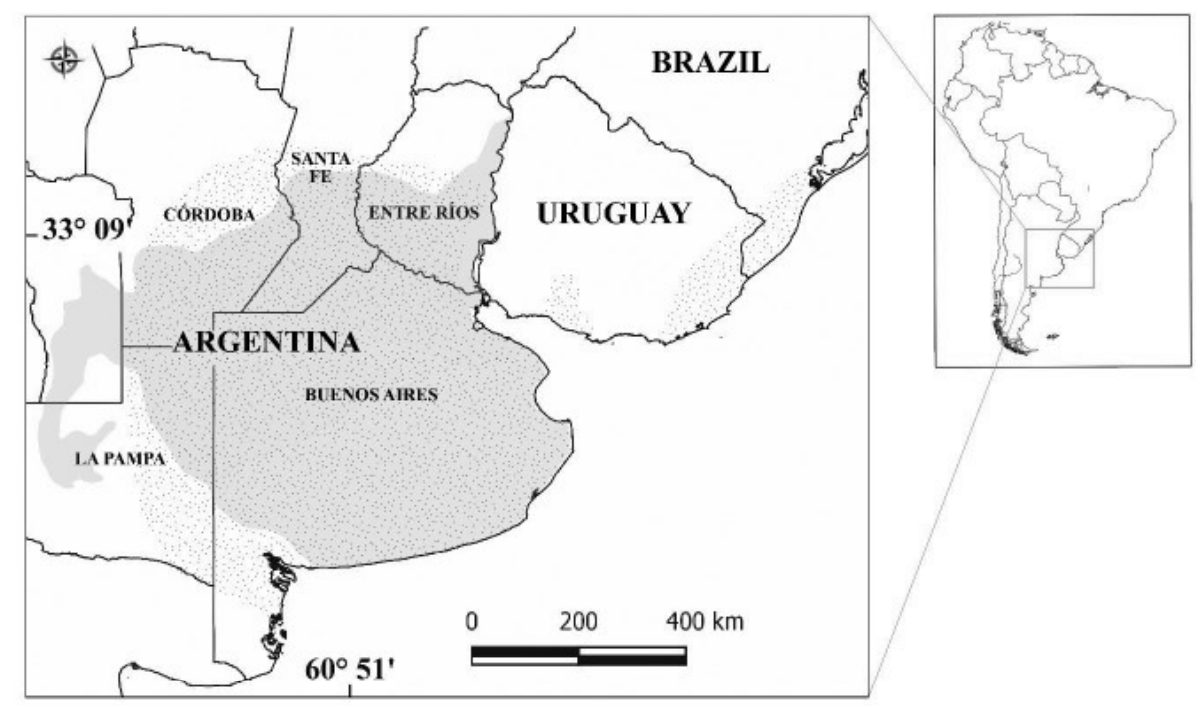

Figura 1. Demarcación de la región pampeana. (Fuente: Fundación Agropecuaria para el Desarrollo de Argentina).

Por supuesto, la cuestión agraria en la Argentina no se reduce a la "pampa gringa”. En el norte argentino (desde el norte cordobés), la ampliación de la frontera agropecuaria llevada a cabo por grandes empresas del sector ha puesto en riesgo formas tradicionales de organización de la agricultura familiar y de subsistencia. De esta tensión han nacido un sinnúmero de agrupaciones que se reivindican campesinas e indígenas y que antagonizan con esos desarrollos. Asimismo, y en los cordones de las grandes urbes, la inmigración boliviana ha introducido un incipiente mercado de producción de hortalizas destinado al consumo de ciudades. Ambas dinámicas son relevantes, pero externas al actor 
Federico Zapata

Peronismo y campo: ¿diálogo imposible? Un abordaje desde la comunicación

conflictivo en cuestión aquí analizado: el productor agropecuario de la región pampeana como un sujeto diferente, tanto del "campesino-indígena" como del "horticultor".

En segundo lugar, la peculiaridad del desarrollo agropecuario argentino en la región pampeana vino dada por la conformación histórica de una modalidad singular de producción: la familiar (farmers o colonos). Hablar de producción familiar implica referirse a sujetos que: a) tienen alguna capacidad de acumulación; b) se ubican en los estratos medios de la estructura social agraria, si consideramos su nivel de ingresos; $c$ ) incluyen la participación de la familia en la gestión y organización laboral; y d) cuya producción está incorporada al circuito internacional (Muzlera, 2013).

Básicamente, el sujeto agropecuario argentino no es un "aristócrata" con orígenes familiares en el siglo XIX que conduce una empresa jerárquica desde la cúspide de un bello casco de estancia con sirvientes. El sujeto agropecuario argentino es un "gringo" o "chacarero" que inmigró al país hacia fines del siglo XIX o principios del siglo XX, proveniente mayoritariamente del centro y norte de Italia (piamonteses, lombardos, friulanos, y los míticos recaudadores de impuestos del vaticano en la Edad Media, los marchegianos, entre otros), que comenzó arrendando pedazos de campo que eran propiedad de la vieja oligarquía terrateniente para trabajarlos con su familia y que, producto de la división de la herencia que impuso el Código Civil de Dalmacio Vélez Sarsfield y de las leyes de arrendamiento sancionadas en el Gobierno de Perón, logró comprar esos pedazos de tierra y hacerse propietario de pequeñas y medianas unidades productivas.

De alguna manera, el Código Vélez Sarsfield terminó impulsando una reforma agraria de facto en Argentina, vía la división de la tierra por herederos individuales. En otras palabras, el Código generó un proceso de debilitamiento de las familias tradicionales que poseían la tierra y, en paralelo, impulsó la conformación de estructuras de tenencia chicas y medianas según la cantidad de hijos que heredaban.

Las leyes de arrendamientos que inauguró el peronismo terminaron de facilitar esa profunda transformación en la tenencia de la tierra, que implicó consolidar la conformación del campo realmente existente: el productor agropecuario de escala familiar. Sin embargo, paradójicamente, la socialización política del sector fue absorbida por las fuerzas conservadoras ante la incapacidad del peronismo de adecuar su discurso a la realidad que sus políticas producían.

En tercer lugar, y a diferencia de lo que preveía la teoría social, los farmers no se encuentran en un estadio de transición, sino que son relativamente estables (Muzlera, 2013). Es decir, el desarrollo del capitalismo agropecuario argentino no se produjo a expensas de ellos, sino que se desarrolló con ellos (Muzlera, 2013). Uno de los factores explicativos de esta estabilidad tiene que ver con el riesgo agrícola: el mayor riesgo de las inversiones agrícolas en comparación con las inversiones industriales (factor climático) y la menor liquidez (debido a la necesidad de esperar los ciclos biológicos de la 
Austral Comunicación

Volumen 9, número 2 (Diciembre de 2020): 429-456. ISSN 2313-9129

producción) que presentan respecto a las inversiones financieras generó en los farmers -aun cuando contaron con acceso a fuentes crediticias- la necesidad y la capacidad de generar sus propios recursos financieros (Muzlera, 2013). Esta capacidad/necesidad de acumulación les dio una relativa estabilidad histórica (Muzlera, 2013). En el campo pampeano, el que no lleva una contabilidad cuáquera desaparece. La década de los 90 es contundente al respecto.

En cuarto lugar, tomando como referencia el trabajo de Muzlera (2013), es posible construir la siguiente tipología de sujetos agrarios en la región pampeana a partir de la identificación de su relación con el territorio, su nivel de capitalización (tierra y equipamiento), su organización, el tipo de actividad y sus relaciones externas: grandes empresas agropecuarias, pools de siembra, productores medianos profesionalizados, pequeños productores familiares, productores unipersonales, rentistas y contratistas. En el caso en estudio, el universo de productores rurales está conformado por los subtipos productores medianos profesionalizados, pequeños productores familiares y productores unipersonales. Las categorías rentistas y contratistas son ya vías de salida del sujeto productor (ver Tabla 1 ).

Tabla 1. Tipología de actores del sector agropecuario

\begin{tabular}{|c|c|c|c|c|c|}
\hline & Territorio & Capitalización & Organización & Actividad & Relaciones externas \\
\hline $\begin{array}{l}\text { Grandes empresas } \\
\text { agropecuarias }\end{array}$ & $\begin{array}{l}\text { Entre } 3000 \text { y } 20000 \text { has (con } \\
\text { diversificación geográfica) }\end{array}$ & $\begin{array}{l}\text { Tierras y } \\
\text { equipamiento } \\
\text { propio. }\end{array}$ & $\begin{array}{l}\text { S.A. con management } \\
\text { profesionalizado. } \\
\text { Contratación de } \\
\text { mano de obra }\end{array}$ & $\begin{array}{l}\text { Agricultura } \\
\text { extensiva y } \\
\text { ganadería }\end{array}$ & $\begin{array}{l}\text { Actores de gran escala } \\
\text { fuera del marco local }\end{array}$ \\
\hline Pools de siembra & $\begin{array}{l}\text { Entre } 1000 \text { y } 300000 \\
\text { has (diversificadas } \\
\text { geográficamente) }\end{array}$ & Tierras alquiladas & $\begin{array}{l}\text { Fideicomisos con } \\
\text { management } \\
\text { profesionalizado }\end{array}$ & $\begin{array}{l}\text { Principalmente } \\
\text { monocultivo (soja) }\end{array}$ & $\begin{array}{l}\text { Actores de gran escala } \\
\text { afuera del marco local }\end{array}$ \\
\hline $\begin{array}{l}\text { Productores medianos } \\
\text { profesionalizados }\end{array}$ & Entre 600 y 3000 has & Tierras propias & $\begin{array}{l}\text { Gerencia familiar con } \\
\text { tercerización de tareas } \\
\text { y empleo endógeno }\end{array}$ & $\begin{array}{l}\text { Agricultura y } \\
\text { ganadería }\end{array}$ & $\begin{array}{l}\text { Actores locales (empresas } \\
\text { y cooperativas) }\end{array}$ \\
\hline $\begin{array}{l}\text { Pequeños productores } \\
\text { familiares }\end{array}$ & Entre 50 y 600 has & $\begin{array}{l}\text { Suelen combinar } \\
\text { tierras propias con } \\
\text { arrendamientos }\end{array}$ & Trabajo familiar & $\begin{array}{l}\text { Agricultura, } \\
\text { ganadería, } \\
\text { lechería, } \\
\text { horticultura, } \\
\text { fruticultura }\end{array}$ & $\begin{array}{l}\text { Actores locales y } \\
\text { cooperativas }\end{array}$ \\
\hline $\begin{array}{l}\text { Productores } \\
\text { unipersonales }\end{array}$ & Entre 50 y 600 has & Tierras propias & $\begin{array}{l}\text { La familia solo conserva } \\
\text { la dirección }\end{array}$ & Agricultura & $\begin{array}{l}\text { Actores locales y } \\
\text { cooperativas }\end{array}$ \\
\hline Minirrentistas & Entre 0 y 600 has & Tierras propias & Bien de familia & Rentista & Empresa arrendataria \\
\hline Contratistas & Con 0 sin tierras & Maquinaria & $\begin{array}{l}\text { Trabajo familiar más } \\
\text { personal temporario }\end{array}$ & Servicios & $\begin{array}{l}\text { Actores locales y } \\
\text { extra-locales }\end{array}$ \\
\hline
\end{tabular}


Repasemos algunas conclusiones que surgen de los datos censales en relación con la dinámica sectorial descriptas. Según el último Censo Nacional Agropecuario, realizado en 2018 (Instituto Nacional de Estadística y Censos, 2019), se identifican en Argentina 250.881 explotaciones agropecuarias (EAP) que cubren 157.423.932,1 hectáreas, con un promedio de 627,5 hectáreas por EAP, aunque las dos terceras partes tienen entre 200 y 500 hectáreas. Es decir, la pequeña y mediana propiedad sigue siendo el epicentro de la producción agropecuaria en la Argentina.

En palabras de Jorge Todesca, director del INDEC al momento de la realización del último Censo Nacional Agropecuario (2018):

El 91\% de los productores explotan sus propias unidades productivas, trabajan y viven en el campo [...] se trata de una enorme clase media agropecuaria que es un desafío a relatos, discursos y preconceptos largamente asentados sobre la estructura del sector (Todesca, 2019, p. 1).

Si nos alejamos un poco y comparamos los datos censales de 2018 con los datos de los anteriores censos, tomando como punto de partida la transición democrática (1983), en apenas tres décadas la cantidad de explotaciones agropecuarias se redujo de 421.221 a 250.881. Esto es, habrían desaparecido por lo menos unos 170 mil productores, un $40 \%$ de los que existían al comienzo de la democracia.

En otras palabras, la falta de políticas adecuadas está produciendo un creciente proceso de concentración de la tierra en Argentina, asociada a la salida de pequeños y medianos productores. Sin embargo, y más allá de esta tendencia, el pequeño y mediano productor sigue siendo dominante (ver Figura 2).

Este Censo desmintió aquella creencia tan urbana de que el campo está manejado por unas pocas familias aristocráticas o terratenientes. Más allá de la visible concentración que se vive en el sector, y el crecimiento de la superficie promedio, buena parte de esa "clase media rural" sobrevive (Longoni, 2019, p. 1).

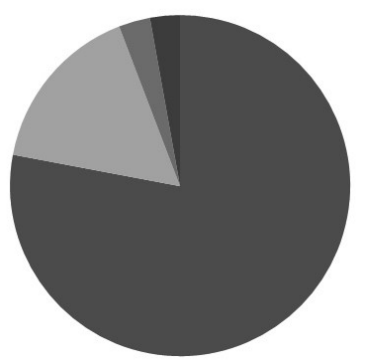

EAP por tipo jurídico

- Personashumanas: $84,5 \%$

-Personas jurídicas: $11,4 \%$ - Sociedades de hechono registradas: $2,1 \%$

- Sin discriminar: $2 \%$

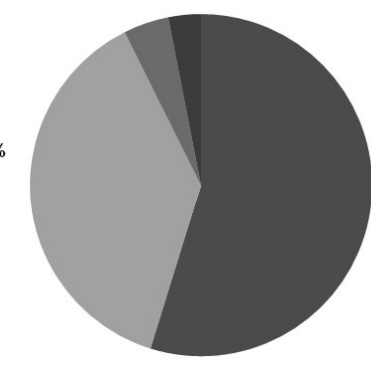

Hectáreas portipo jurídico

- Personashumanas: $54,8 \%$

- Personas jurídicas: $37,8 \%$

- Sociedades de hechono registradas: $4,3 \%$

- Sin discriminar: $3,1 \%$

Figura 2. Explotaciones y superficies agropecuarias por tipo jurídico (Fuente: Censo Nacional Agropecuario 2018).

En relación con el género, el 78\% de las 211.928 explotaciones agropecuarias conducidas con el tipo jurídico "personas humanas" era administrado por productores 
Austral Comunicación

Volumen 9, número 2 (Diciembre de 2020): 429-456. ISSN 2313-9129

varones; y el 20\%, por mujeres. Por su parte, el epicentro etario era el rango 40-64 años, que concentra al $54 \%$ de los productores para el caso de personas humanas o físicas. Sin embargo, en los extremos se visualiza un proceso de envejecimiento de la pirámide: el rango menor de 39 años ocupa el 16\%, contra el rango de mayores de 65 años que ocupa el 29\%. De no mediar políticas de estímulo al sector, esta dinámica de expulsión de poblaciones jóvenes hacia ciudades va a profundizarse en paralelo con el incipiente proceso de concentración de la tierra. Es decir, la salida de pequeños y medianos productores de la actividad es paralela al abandono de los hijos e hijas de la trayectoria productiva de los padres (ver Figura 3).
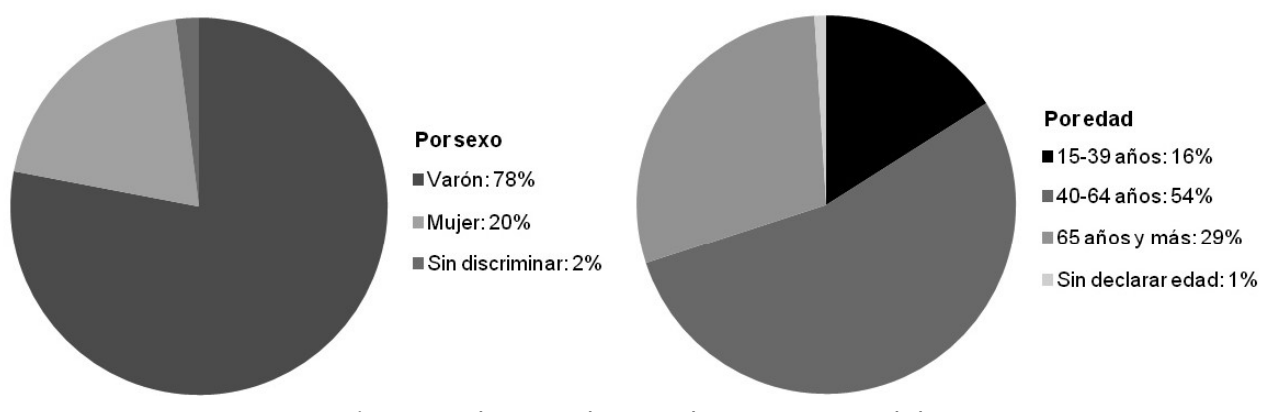

Figura 3. Explotaciones de persona humana por sexo y edad. (Fuente: Censo Nacional Agropecuario 2018).

Por su parte, la distribución de parcelas en la geografía nacional muestra un fuerte predominio de la región pampeana con una creciente y pujante ampliación de la frontera hacia el norte.

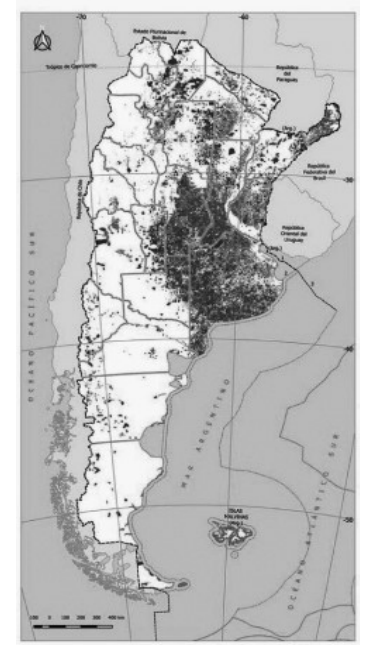

Figura 4. Parcelas censadas con algún cultivo. (Fuente: Censo Nacional Agropecuario 2018). 
Federico Zapata

Peronismo y campo: ¿diálogo imposible? Un abordaje desde la comunicación

\section{La tensión entre comunicación y cultura}

El relato fundacional del peronismo con respecto al sector agropecuario (19451955), aunque nacido hace más de 70 años, sigue operando en los sectores del peronismo nacional como una caja de herramientas interpretativas a las cuales poder recurrir en momentos en los que se producen tensiones discursivas en el ámbito público.

El problema con este marco conceptual es que, como se especificó en el aparatado que analiza la estructura sectorial "realmente existente", describe de una manera distorsionada y despectiva la realidad territorial a la que se refiere/interpela y funciona como una trinchera que obstaculiza la relación/comunicación entre peronismo nacional y territorio agropecuario.

En términos de la caja de herramientas de ideas, el peronismo nacional sigue utilizando la vía junker para describir al sector agropecuario argentino, que, sin embargo, es un caso de vía farmer. En otros términos, lo que para el peronismo nacional es un desarrollo capitalista "desde arriba" (oligarquía), funciona en la realidad como un desarrollo capitalista "desde abajo" (productores).

¿Por qué el peronismo nacional sigue recurriendo a una narrativa conceptual añosa que describe de manera distorsionada la realidad que pretende interpelar? La explicación tiene que ver, en parte, con el hecho de que el peronismo nacional se ha nutrido desde 2003 de cuadros políticos provenientes mayoritariamente de tres orígenes geográficos: patagónicos centrodesarrollistas, porteños progresistas y bonaerenses industrialistas del primer, segundo y tercer cordón del conurbano.

Este hecho tiene repercusiones relevantes. En primer lugar, porque los tres grupos provienen de realidades geográficas lejanas al sujeto productor agropecuario. En segundo lugar, porque al no existir referentes empíricos en los tres territorios, los dirigentes no recurren a la experiencia para construir una narrativa, sino a representaciones históricas ancladas en la cosmovisión dominante del peronismo del Río de la Plata.

Para ejemplificar este proceso cognitivo, repasemos la construcción del marco discursivo del kirchnerismo a partir de la crisis con el sector agropecuario (2008):

1. Identificación de la politización del sector agropecuario (movilización) con la inestabilidad no democrática de la Argentina reciente: dictadura y Semana Santa (levantamiento carapintada). Es decir, la movilización del sector per se desplaza la frontera entre lo legítimo-legal y lo ilegítimo-ilegal. En otras palabras, para el discurso, el campo puede producir en forma legítima y legal, pero no puede protestar en forma legítima y legal. Traspasar esa frontera implica poner en cuestión la democracia argentina: 


\begin{abstract}
Las imágenes que me tocó ver este fin de semana largo, aquí en la República Argentina, casualmente en Semana Santa, siempre Semana Santa ha sido emblemática para los argentinos, y como si fuera una señal pegada, en esta oportunidad, a la memoria de una de las peores tragedias que tiene la historia Argentina, y que fue la del 24 de marzo de 1976. Son señales tal vez que se toma la historia, la casualidad, pero lo cierto es que, en estos cinco días, el último día fue 24 de marzo (Fernández, 2008).
\end{abstract}

2. Identificación del sector agropecuario con un actor egoísta en la vida nacional, alejado de las grandes mayorías, con un proyecto excluyente de orden social. En otras palabras, la definición de "oligarquía": sectores dominantes de la agricultura argentina, tradicionalmente opuestos a la industrialización del país y a los procesos de distribución social del ingreso. Es decir, el discurso busca recrear una frontera entre mayorías (urbanas, industriales y democráticas) y minorías (rurales, agropecuarias y autoritarias), en la que la protesta del segundo grupo viene a poner un coto a la ampliación de derechos y consumos del primer grupo:

Recuerdo esa Argentina de los años 2003, 2002, 2001, miles de argentinos en piquetes, cortando calles, rutas porque les faltaba trabajo, porque hacía años que habían perdido su trabajo o, tal vez, en el 2001, porque se habían apropiado de los depósitos de pequeños ahorristas de la clase media, Eran los piquetes, como digo yo, de la miseria y la tragedia de los argentinos. [...] Este último fin de semana largo nos tocó ver la contracara, lo que yo denomino los piquetes de la abundancia, los piquetes de los sectores de mayor rentabilidad. [...] Hay una rara conducta, muchas veces, es como que cuando hay pérdidas la sociedad debería absolverlas, es una suerte de socialización de las vacas flacas y cuando las vacas vienen gordas, las vaquitas para ellos y las penitas para los demás. [...] Está bien, nadie critica que puedan comprarse una 4 por 4 o que vivan bien y que tengan lo que tantísimos argentinos querrían tener; lo que no me parece bien es que además quieran hacerlo a costa de que otros argentinos no puedan acceder a las cuestiones más elementales. [...] La huelga me parece que se la están haciendo a los argentinos, porque las exportaciones siguen viento en popa. [...] Pero esto es lo que yo digo qué país queremos, si queremos volver al país de unos poquitos o queremos volver a un país más justo, con mayor equidad, con mayor distribución. Porque las retenciones no son medidas fiscales, son profundas medidas redistributivas del ingreso (Fernández, 2008).

Por eso, con la firmeza en las convicciones, con la firmeza en las ideas [...] muchos de ellos ni siquiera cambiaron los collares, son los mismos. Por eso debemos tenerlo absolutamente presente y por eso nuestra clase media, que fue lamentablemente instrumentada muchas veces, tiene que darse cuenta de que nunca van a encontrar la solidaridad de los sectores de la oligarquía argentina; sí van a encontrar la solidaridad de los trabajadores, de los intelectuales, de los estudiantes, de toda la patria. Por eso la clase media argentina se encuentra acá (Kirchner, 2008).

Si la explicación de esta tensión es en parte la resultante del origen geográfico de los cuadros del peronismo nacional en los últimos 17 años, deberían existir procesos o casos subnacionales en los que esta correlación se rompa. Es decir, la contracara de esta dinámica debería ser la relación del peronismo subnacional en provincias donde sí exista un referente empírico cercano. 
Tomemos el ejemplo de Córdoba. Allí, el peronismo gobierna desde hace más de 20 años. Ha gobernado en democracia más que el radicalismo provincial, configurando una hegemonía provincial estable y competitiva. Gobierna una provincia productiva tricéfala: un centro urbano con perfil industrial y de servicios, una miríada de pequeñas localidades "pampeanas" articuladas en torno a complejos agroindustriales de diferente complejidad y un cordón de regiones serranas ordenadas en función del turismo.

¿Cómo logró el peronismo en una provincia con estas características socioproductivas construir una coalición social estable y hegemónica? La facción que tomó las riendas del peronismo cordobés luego de 1983 fusionó los elementos conceptuales de la renovación (institucionalización y democracia partidaria) con una teoría de la economía del conocimiento, y como esta es transversal a los tres sectores mencionados (agropecuario, industrial y servicios), edificó una fuerte coalición social cuyo engranaje de conexión es el desarrollo productivo, no el desarrollo del Estado. El desarrollo y la diversificación del mercado están en el epicentro del dispositivo gubernamental.

Los dos grandes ideólogos de este desplazamiento son prototípicos. Por un lado, Juan Manuel de la Sota, uno de los referentes de la renovación a nivel nacional, un líder pragmático con una capacidad extraordinaria para caminar y entender la realidad cultural de su provincia. Por otro lado, su amigo y socio político, Juan Schiaretti, un cuadro formado en el peronismo combativo de los 70, pero con una fuerte impronta intelectual en el campo de la economía y experiencia en el management privado (en su exilio), lo que le permitió desarrollar una visión no Estado-céntrica del desarrollo inclusivo.

Uno de los pilares de la coalición social que ambos referentes diseñaron fue el sector agropecuario, en el que el peronismo local se impone electoralmente, gobierna y transforma territorios. Un caso emblemático son las gestiones de la ciudad de Villa María entre 1999 y la actualidad. Allí, el peronismo cordobés lideró un proyecto de fuerte transformación que, en el plazo de 20 años, posicionó a la ciudad como un nuevo polo de desarrollo provincial (al nivel de Río Cuarto), agregándole valor al entorno agropecuario: agro-servicios, bioeconomía, logística, conocimiento.

\section{Conclusión: aportes de la comunicación política a la constitución de coaliciones empresariales}

Retomamos, entonces, la pregunta central: ¿qué lecciones puede, el peronismo nacional, extraer de la experiencia del peronismo subnacional -en este caso, el cordobéscon relación al sector agropecuario "realmente existente"? Desde el punto de vista de la comunicación política y la teoría de las coaliciones sociales y empresariales, es posible pensar cuatro hipótesis de trabajo. 
Austral Comunicación

Volumen 9, número 2 (Diciembre de 2020): 429-456. ISSN 2313-9129

En primer lugar, el campo no es un enemigo natural del peronismo. Si el peronismo se transforma en un proyecto de modernización inclusiva con foco en las exportaciones, posiblemente pueda contar en su coalición con un actor socio-productivo, que es, paradójicamente, mucho más innovador que el tradicional sector industrial nacional. El Gobierno de Eduardo Duhalde (2002-2003) y el de Néstor Kirchner (2003-2007), de hecho, contaron en su coalición "informal" con el sector agropecuario.

En segundo lugar, el campo requiere un abordaje empírico, práctico, que parta de la composición real del sector y que diversifique mensajes, políticas y canales según el referente al que se pretenda interpelar. Por un lado, pequeños y medianos productores articulados en sistemas cooperativos, con esquemas gremiales de representación ("los gringos"). Por el otro, los grandes jugadores industriales del sector (exportadoras y grandes empresas agroindustriales). No son lo mismo y requieren estrategias de abordaje diferentes. Sin perder de vista que, en la base de sustentación de una coalición con el sector, siempre estarán los productores. Los "gringos" primero.

En tercer lugar, el peronismo nacional debe revisar, en forma honesta, su repertorio conceptual sobre el sector. Acercarse, conocerlo, entenderlo. De primera mano, sin intermediaciones conceptuales. Esa es la mejor garantía para romper las estigmatizaciones. Si el peronismo nacional define suturar la grieta con el sector y su territorio, deberá clausurar la retórica épica del peronismo del Río de la Plata ("reforma agraria", "IAPI o Instituto Argentino de Promoción del Intercambio", "oligarquía"). Esos relatos pueden parecer reales para un diputado de la Ciudad Autónoma de Buenos Aires, de Mendoza o de Neuquén precisamente porque desconocen en profundidad la realidad a la que interpelan. Con el agravante de que, desde la realidad del sector y su territorio, ese marco discursivo es vivenciado como una caracterización ofensiva.

En cuarto lugar, los productores agropecuarios desconfían de las regulaciones, y las políticas regulatorias también son una forma de comunicación. Para el sector, siempre una regulación implica un engorroso trámite sujeto a arbitrariedades administrativas. El esquema de segmentación y devolución de retenciones por escala, o los ROE (Registros de Operaciones de Exportación), son ejemplos de esas experiencias negativas con la estatalidad. El campo necesita al Estado, pero lo necesita invirtiendo, generando bienes públicos, mejorando la competitividad de los productores argentinos para exportar más y mejor al mundo: rutas, puertos, caminos rurales, infraestructura de conectividad, simplificación fiscal, financiación de proyectos público-privados para innovación en materiales, bioeconomía y software. Menos regulación. Más inversión. Un lenguaje común desde el punto de vista de la política pública.

El presente artículo ha buscado demostrar que lo que parece un antagonismo "natural" encierra en realidad una construcción histórico-cultural, la cual puede ser redefinida en términos cooperativos a partir de una estrategia de comunicación política 
Federico Zapata

Peronismo y campo: ¿diálogo imposible? Un abordaje desde la comunicación

que ponga en el centro de la escena a la cultura y a la identidad. Quedan abiertas líneas de investigación-acción futuras. Desde el punto de vista de la planificación estratégica, resulta central profundizar en el conjunto de valores, visiones y misiones que animan al sector agropecuario de la región pampeana, de modo de identificar posibles sinergias que faciliten la emergencia de un ecosistema colaborativo público-privado de cara a los desafíos nacionales de corto, mediano y largo plazo.

\section{Referencias}

Amadeo,B. (2016).El estudio dela comunicación gubernamental:líneas de investigación y futuros desafíos. Revista Austral Comunicación, 5(2), 155-181. Obtenido en julio de 2020 de https://doi.org/10.26422/aucom.2017.0502.ama.

Barsky, O. y Dávila, M. (2008). La rebelión del campo. Historia del conflicto agrario argentino. Buenos Aires: Sudamericana.

Bisang, R., Anlló, G. y Campi, M. (2008). Una revolución (no tan) silenciosa. Claves para repensar el agro en Argentina. Desarrollo Económico, (190/191), p. 165-207.

Canel, M. J. (2006). Comunicación política. Una guía para su estudio y práctica. Madrid: Tecnos.

D’Adamo, O. y García Beaudoux, V. (2013). Arquitectura del relato político. Storytelling al servicio de la comunicación política.En Crespo,I.y Del Rey,J.(eds.).Comunicación política y campañas electorales en América Latina (pp. 55-68). Buenos Aires: Biblos.

Elizalde, L. (2009). Gestión de la comunicación pública. Empresas, grupos e instituciones en el escenario público. Barcelona: Editorial Bosch.

Fernández, C. (2008). Discurso del 25 de marzo sobre el lock-out patronal del campo. Obtenido en julio de 2020 de https://www.cfkargentina.com/tag/ discursos-de-cristina/.

Fundación Agropecuaria para el Desarrollo de Argentina. (2019). El campo en números. Informe FADA. Río Cuarto: Córdoba.

Hora, R. (2010). La crisis del campo del otoño de 2008. Desarrollo Económico, (197), p. 81111.

Hora, R. (2015). Los terratenientes de la pampa argentina. Una historia social y política, 1860-1945. Buenos Aires: Siglo XXI.

Hora, R. (2018). ¿Cómo pensaron el campo los argentinos? Y cómo pensarlo hoy, cuando ese campo ya no existe. Buenos Aires: Siglo XXI.

Instituto Nacional de Estadística y Censos. (2019). Censo Nacional Agropecuario 2018: resultados preliminares. Ciudad Autónoma de Buenos Aires: Instituto Nacional de Estadística y Censos.

Kautsky, K. (1983). La cuestión agraria. Análisis de las tendencias de la agricultura moderna y de la política agraria de la socialdemocracia. México: Siglo XXI. 
Austral Comunicación

Volumen 9, número 2 (Diciembre de 2020): 429-456. ISSN 2313-9129

Kirchner, N. (2008). Discurso en la Plaza de los Dos Congresos. Conflicto del Campo. Sitio Oficial. Obtenido en julio de 2020 de https://www.cfkargentina.com/tag/ discursos-de-cristina/.

Lattuada, M. (1986). La política agraria peronista (1943-1983). Buenos Aires: CEAL.

Lattuada, M. (2002). El peronismo y los sectores sociales agrarios. La resignificación del discurso como articulador de los cambios en las relaciones de dominación y la permanencia de las relaciones de producción. Mundo Agrario, 3(5), s.p. Obtenido en julio de 2019 de http://www.memoria.fahce.unlp.edu.ar.

Lenin, V. (1957). El desarrollo del capitalismo en Estados Unidos. En Obras completas (Tomo XXIII, pp. 135-238). Buenos Aires: Cartago.

Longoni, M. (2019). El Censo Agropecuario confirmó que desde 2002 se extinguió un productor agropecuario cada dos horas. Bichos de Campo. Obtenido en julio de 2020 de https://bichosdecampo.com/el-censo-agropecuario-confirmo-que-desde2002-se-extinguio-un-productor-agropecuario-cada-dos-horas.

Marx, K. (2002). El capital. Buenos Aires: Siglo XXI.

Muzlera, J. (2008a). Agricultura familiar. En Biaggini, H. y Roig, A. (eds.). Diccionario del Pensamiento Alternativo II. Buenos Aires: Biblos. Obtenido en julio de 2019 de http://www.cecies.org/.

Muzlera, J. (2008b). Chacarero. En Biaggini, H. y Roig, A. (eds.). Diccionario del Pensamiento Alternativo II. Buenos Aires: Biblos. Obtenido en julio de 2019 de http://www.cecies.org/.

Muzlera, J. (2009a). Transformaciones, continuidades y tensiones en el mundo chacarero. La herencia en la pampa gringa. En Gras, C. y Hernández V. (eds.). La Argentina rural. De la agricultura familiar a los agronegocios (pp. 135 - 153). Buenos Aires: Biblos.

Muzlera, J. (2009b). Chacareros del siglo XXI. Herencia, familia y trabajo en la Pampa Gringa. Buenos Aires: Imago Mundi.

Muzlera, J. (2013). La modernidad tardía en el agro pampeano: sujetos agrarios y estructura productiva. Bernal: Universidad Nacional de Quilmes.

Perón, J. D. (1945). Discurso de Juan Domingo Perón desde el balcón de la casa de gobierno en plaza de Mayo el 17 de octubre de 1945. Buenos Aires: Archivos Históricos. Obtenido de https://cdn.educ.ar/repositorio/Download/ file?file_id=fff94e12-322f-4c73-94f7-76cd229c3bb5.

Perón, J. D. (1952). Los mensajes de Perón. Buenos Aires: Mundo Peronista.

Perón, J. D. (1973). Discurso del 14 de diciembre ante la CGT. Buenos Aires: Secretaría de Prensa y Difusión, Presidencia de la Nación Argentina.

Pierson, P. y Skocpol, T. (2002). Historic Institutionalism in Contemporary Political Science. En Katznelson, I. y Milner, H. V. (eds.). Political Science: State of the Discipline (pp. 693-721). Nueva York: W. W. Norton. 
Peronismo y campo: ¿diálogo imposible? Un abordaje desde la comunicación

Riorda, M. (2006). Hacia un modelo de comunicación gubernamental para el consenso. En Elizalde, L., Fernández Pedemonte, D. y Riorda, M., La construcción del consenso: gestión de la comunicación gubernamental. Buenos Aires: La Crujía Ediciones.

Sarmiento, D. F. (1978). Facundo. Civilización y barbarie. Buenos Aires: Colihue. Stinchcombe, A. L. (1987). Constructing Social Theories. University of Chicago Press.

Todesca, J.(2019). Presentación resultados preliminares del Censo Nacional Agropecuario. Conferencia de Prensa, Instituto Nacional de Estadística y Censos.

Wendt, A. (1992). Anarchy is what States Make of it: The Social Construction of Power Politics. International Organization, 46(2), pp. 391-425.

Wendt, A. (1999). Social Theory of International Politics. Cambridge: Cambridge University Press.

Wolton, D. (2005). Pensar la Comunicación. Buenos Aires: Prometeo Libros. 